\title{
Evaluation of the Severity of Maxillo-Facial Injuries by Motorcycle Road Accident in the Teaching Hospital of Conakry: A Case-Control Study
}

\author{
Oumar Raphiou Diallo', Alpha Oumar Diallo², Karamoko Alpha Diallo', Alhassane Conde \\ ${ }^{1}$ Department of Odontostomatology and Maxillo-Facial Surgery National Hospital of Donka, Conakry, Guinea \\ ${ }^{2}$ Department of ENT National Hospital of Ignace Deen, Conakry, Guinea \\ Email: rafioumajid@yahoo.fr
}

How to cite this paper: Diallo, O.R., Diallo, A.O., Diallo, K.A. and Conde, A. (2021) Evaluation of the Severity of Maxillo-Facial Injuries by Motorcycle Road Accident in the Teaching Hospital of Conakry: A Case-Control Study. Open Journal of Stomatology, 11, 107-118.

https://doi.org/10.4236/ojst.2021.113009

Received: November 1, 2020

Accepted: March 1, 2021

Published: March 4, 2021

Copyright $\odot 2021$ by author(s) and Scientific Research Publishing Inc. This work is licensed under the Creative Commons Attribution International License (CC BY 4.0).

http://creativecommons.org/licenses/by/4.0/

\begin{abstract}
Introduction: Maxillofacial injuries caused by motorcycle road accidents are serious and represent a real public health issue. They mainly affect young adult males. The objectives of this study were to determine the frequency of motorcycle road accidents, describe the socio-demographic characteristics of the injured, determine the degree of severity of motorcycle injuries compared to car injuries, and describe the therapeutic modalities. Materials and Method: This study was a prospective case-control study carried out in the Department of Odontostomatology, Maxillofacial Surgery and Surgical Emergencies at the National Hospital of Donka. The data was collected over a period of six months from January 1st to June 30th, 2017. All victims of road accidents by motorcycle (cases) or car (controls) that received care and post-surgical follow up were included. Results: A total of 505 patients with maxillofacial injuries were reviewed during the period of the study. From the review, 205 (40.6\%) motorcycle accidents were recorded as "cases" and 109 (21.58\%) car accidents were classified as "controls" group. Men were the most affected in both groups, $\mathrm{n}=254$ (177 males in the case group and 77 in the control $)(p=0.01)$. There was a proportionate relationship between helmet use and death $(\mathrm{p}=0.015)$. A motorcycle accident victim is more likely to develop a mandibular fracture $(p=0.029)$ and limb injury $(p=0.034)$ when compared to a car accident victim. However, there was no significant difference between cases and controls for head trauma $(p=0.4878)$, Facial Injury Severity Scale (FISS) $(\mathrm{p}=0.130)$, and Glasgow score $(\mathrm{p}=0.709)$. Conclusion: Maxillofacial injuries caused by motorcycle accidents are increasing in Guinea. Young adult males have the highest incidence of motorcycle accidents.
\end{abstract}


The death rate related to motorcycle road accidents is high, and mandatory use of a helmet for all drivers and passengers is recommended. These preventative actions could reduce the mortality and morbidity of motorcycle road accidents in Guinea.

\section{Keywords}

Severity, Maxillofacial Trauma, Motorcycle, Case-Control

\section{Introduction}

Maxillofacial injuries from road accidents are common and affect a young population, with men being the most affected victims [1]. Road accidents by motorcycles are prevalent throughout the world, but particularly affect developing countries. Maxillofacial traumas by motorcycles are serious and they constitute a real public health problem [2]. Motorcycles are the most dangerous form of motorized transportation; motorcycles are about 3 times more likely than passenger car occupants to be injured in a crash, and 16 times more likely to die per vehicle miles traveled [3].

The epidemiological data on maxillofacial injuries vary from one country to another. In Australia, for example, motorcycle fatality and serious injury rates per kilometer travelled are 29 and 37 times higher, respectively, than for other vehicle types [3]. The motorcycle accident mortality rate in India, Indonesia and Malaysia accounts for $27 \%, 42 \%$ and $57 \%$ of all road accidents [4]. In $2008, \mathrm{Li}$, Y., et al. [5] reported that China's motorcycle accidents had resulted in 26,200 dead and 157,500 injured. The mortality per 10,000 and the ratio of deaths to injuries were lower in motorcycles than automobiles, but the mortality per 100 motorcycle accidents was significantly higher than that of automobiles $(\mathrm{p}<$ 0.01). In Brazil from 1996 to 2011, the number of deaths of motorcyclists in Brazil increased 32.1\% [6]. A study conducted in 2010 from Conakry, Diallo, O.R., et al. [7] reported that $61.17 \%$ of cases of maxillofacial injuries were caused by a motorcycle accident.

Facial injuries have clinical varieties because of the location, nature and severity of the affected elements [8]. In Nigeria, Ogini, F.O., et al. [9] reported Glasgow scale of injuries due to motorcycle accidents ranked from 5 - 15. In the same study, femur fractures were associated with maxillofacial trauma in $30.8 \%$ of the cases and the facial injury severity scale (FISS) ranged from 1 - 10.

During the last few decades, the management of maxillofacial trauma has evolved and improved. However, these injuries still represent a major challenge, because they may present as emergencies with life threatening injuries [10]. Maxillofacial injuries that commonly occur in motorcycle accidents pose significant psychological, functional and aesthetic problems to both riders and passengers [11].

The objectives of this study were to determine the frequency of maxilla-facial 
injuries by motorcycle, describe the socio-demographic characteristics of the traumatized, determine the degree of severity of maxilla-facial injuries caused by motorcycle road accidents compared to car road accidents, and describe the therapeutic modalities.

\section{Materials and Method}

This was a prospective case-control study carried out at the Department of Odontostomatology and Maxillofacial Surgery and the Department of Medical and Surgical Emergencies at the National Hospital of Donka. It took place over a period of six months from January 1st, 2017 to June 30th, 2017. Inclusion Criteria: For the cases, the criteria of inclusion were all patients who were victim of a maxillofacial injuries by motorcycle who received treatment and postoperative follow-up.

The controls: all patients who were victims of maxillofacial injuries by car and received a management and a postoperative follow-up. Exclusion Criteria: We excluded 1) patients admitted for maxillofacial injuries by road accident (motorcycle, car), but who did not receive care; and 2) patients admitted for maxillofacial injuries that have not been caused by a road accident. Data analysis: epidemiological, clinical and therapeutic variables have been analyzed. To assess the severity of the injury, the facial injury severity scale (FISS) developed by Baghrei, et al. [12] was used. The assessment of treatment outcomes was based on the following criteria: Good: when the patient was cured without aesthetic and functional sequelae; Satisfactory: when the patient has corrective cosmetic and/or functional sequelae; Bad: when the patient has non-corrective cosmetic and/or functional sequelae. The data was analyzed with the Epi-info software, using version 3.5.1.

To compare the qualitative variables, a Chi- 2 test was applied and an exact Fisher test when the expected values were less than 5 with a significance threshold for $\mathrm{p} \leq 0.05$.

For this study, ethical approval has been obtained from the Ethics Committee of the Ministry of Health and written consent was obtained from all patients.

\section{Results}

During the period of the study, 505 cases of maxillofacial injuries were reviewed. Between them 314 patients satisfied inclusion criteria and 205 (40.6\%) patients were the case group; 109 (21.58\%) were the control group.

Table 1. Comparison of cases and controls by gender.

\begin{tabular}{cccc}
\hline Gender & Female & Male & Total \\
\hline Cases & 28 & 177 & 205 \\
Controls & 32 & 77 & 109 \\
Total & 60 & 254 & 314 \\
\hline
\end{tabular}

$\mathrm{p}=0.001$ 
Table 2. Comparison of cases and controls by age.

\begin{tabular}{cccc}
\hline Age & Cases & Controls & Total \\
\hline $0-15$ & 25 & 18 & 43 \\
$16-30$ & 107 & 50 & 157 \\
$31-45$ & 49 & 27 & 76 \\
$46-60$ & 15 & 13 & 28 \\
$>60$ & 9 & 1 & 10 \\
Total & 205 & 109 & 314 \\
\hline
\end{tabular}

$p=0.167$; Mean age: Cases 28 years; Controls: 29.3 years.

Table 3. Comparison of cases and control by profession.

\begin{tabular}{cccc}
\hline Profession & Cases & Controls & Total \\
\hline Driver & 20 & 21 & 41 \\
Merchant & 34 & 13 & 47 \\
Students & 55 & 32 & 87 \\
Functionary & 27 & 8 & 35 \\
Housewife & 13 & 13 & 26 \\
Worker & 14 & 15 & 29 \\
Others & 36 & 13 & 49 \\
Total & 205 & 109 & 314 \\
\hline
\end{tabular}
$\mathrm{p}=0.02$.
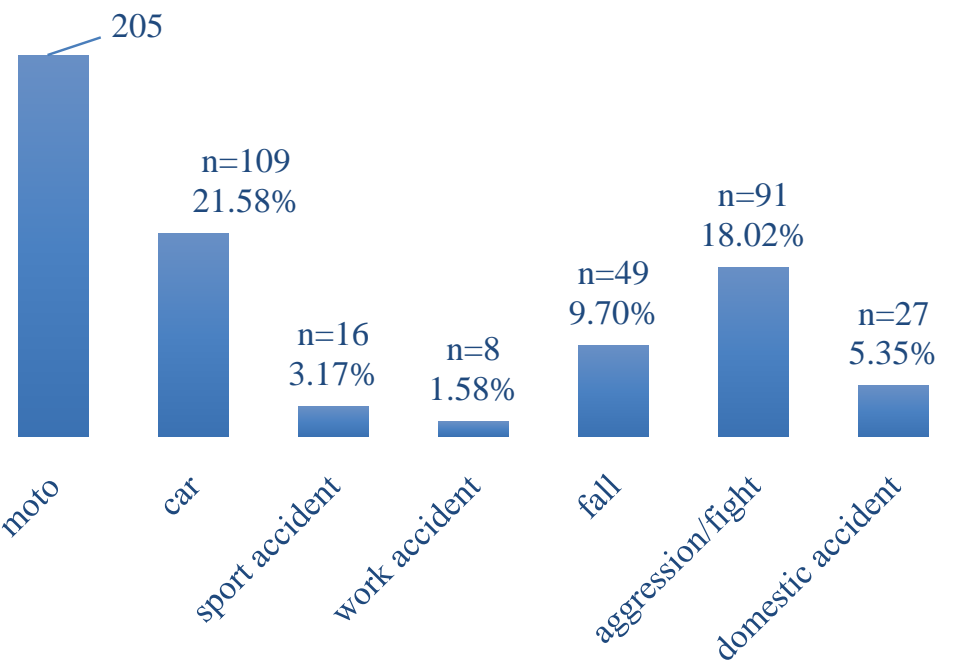

Figure 1. Distribution of all cases of maxillofacial injuries according to etiology.

According to helmet wearing among cases, $45.85 \%$ were wearing helmet $(\mathrm{n}=$ $94)$ and $54.15 \%(n=111)$ were not wearing it. 
The distribution of cases and controls according to the therapeutic indications showed that osteosynthesis was performed in cases in $71.70 \%(\mathrm{n}=147)$ and in controls in $43.12 \%(\mathrm{n}=47)$. Orthopedic treatment was performed in $28.30 \%$ cases patients $(n=58)$ and in $56.88 \%(n=62)$ of the controls group.

Table 4. Distribution of cases by type of victims.

\begin{tabular}{ccc}
\hline Victim type & Frequency & Percentage (\%) \\
\hline Drivers & 121 & 59.02 \\
Passengers & 34 & 16.59 \\
Pedestrians & 50 & 24.39 \\
Total & 205 & 100.00 \\
\hline
\end{tabular}

Table 5. Relationship between helmet wear and death occurrence.

\begin{tabular}{cccc}
\hline Helmet port & Death & living & Total \\
\hline Yes & 3 & 95 & 98 \\
No & 13 & 94 & 107 \\
Total & 16 & 189 & 205 \\
\hline
\end{tabular}

$\mathrm{p}=0.015$, Odds ratio $=4.3$.

Table 6. Comparison of cases and controls by facial injury severity scale (FISS).

\begin{tabular}{ccccc}
\hline FISS & $\mathbf{0 - 3}$ & $\mathbf{4}-\mathbf{6}$ & $\mathbf{2 7}$ & Total \\
\hline Cases & 154 & 37 & 14 & 205 \\
Controls & 83 & 24 & 2 & 109 \\
Total & 237 & 61 & 16 & 314 \\
\hline
\end{tabular}

$\mathrm{p}=0.131$.

Table 7. Relationship between gear type and death.

\begin{tabular}{cccc}
\hline \multirow{2}{*}{ Gear type } & Death & Total & To \\
\cline { 2 - 4 } & Yes & 189 & 205 \\
Motorcycles & 16 & 101 & 109 \\
Cars & 8 & 290 & 314 \\
\hline
\end{tabular}

$\mathrm{p}=0.883$, Odds ratio $=1.07$.

Table 8. Comparison of cases and controls according to mandibular fractures.

\begin{tabular}{cccc}
\hline Gear type & mandibular fracture & Without mandibulaire fracture & Total \\
\hline Motocycle & 79 & 126 & 205 \\
Car & 29 & 80 & 109 \\
Total & 108 & 206 & 314 \\
\hline
\end{tabular}

$\mathrm{p}=0.029$, Odds ratio $=1.63$. 
Table 9. Relationship between cases and controls and fractures of the mid face.

\begin{tabular}{cccc}
\hline Gear type & Mid-face fracture & Without mid-face fracture & Total \\
\hline Cases & 80 & 125 & 205 \\
Controls & 30 & 79 & 109 \\
Total & 110 & 204 & 314 \\
\hline
\end{tabular}

$\mathrm{p}=0.029$, Odds ratio $=1.68$.

Table 10. Comparison of cases and controls by Glasgow score.

\begin{tabular}{ccccc}
\hline Gear type & $>12$ & $\mathbf{8}-\mathbf{1 2}$ & $\mathbf{5 8}$ & Total \\
\hline Cases & 187 & 11 & 7 & 205 \\
Controls & 100 & 4 & 5 & 109 \\
Total & 287 & 15 & 12 & 314 \\
\hline
\end{tabular}

$\mathrm{p}=0.709$

Table 11. Comparison of cases and controls according to the associated lesions.

\begin{tabular}{cccc}
\hline Gear type & associated lesions & Without associated lesions & Total \\
\hline Cases & 86 & 119 & 205 \\
Controls & 38 & 71 & 109 \\
Total & 124 & 190 & 314 \\
\hline
\end{tabular}

$\mathrm{p}=0.221$.

Table 12. Comparison of cases and controls by location of associated lesions.

\begin{tabular}{cccc}
\hline Associated lesions & Cases & Controls & P-value \\
\hline ENT-lesions & 48 & 27 & 0.788 \\
Cervical lesions & 21 & 19 & 0.516 \\
Ocular lesions & 26 & 12 & 0.665 \\
Limb injuries & 42 & 34 & 0.035 \\
\hline
\end{tabular}

Table 13. Comparison of cases and controls by duration of follow-up.

\begin{tabular}{cccc}
\hline Gear type & $\mathbf{2} \mathbf{- 4}$ weeks & $\mathbf{5} \mathbf{- 8}$ weeks & $\mathbf{9} \mathbf{- 1 2}$ weeks \\
\hline Cars & 43 & 8 & 4 \\
Motocycles & 52 & 17 & 25 \\
Total & 95 & 25 & 29 \\
\hline
\end{tabular}

$\mathrm{p}=0.008$

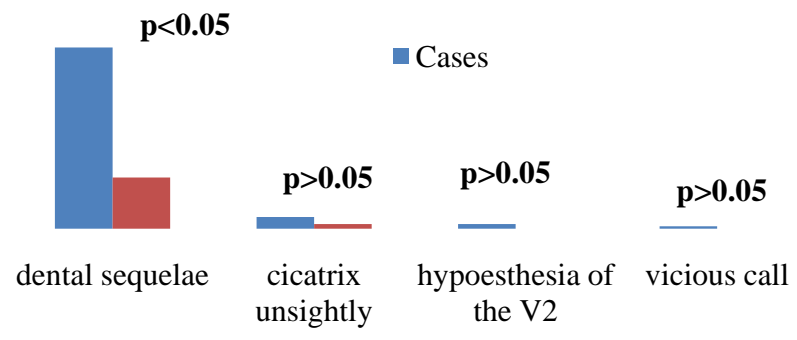

Figure 2. Comparison of cases and controls according to sequelae. 


\section{Discussion}

During the study period, 205 cases of maxillofacial injuries resulting from motorcycle accidents out of a total of 505 patients were reviewed, ie a frequency of 40.59\%. Similar results were published in literature. A study by Diallo, O.R., et al. [7] in Guinea found $39.36 \%$ of road accidents were motorcycle accidents. In Brazil, Nóbrega, L.M., et al. [13] found that motorcycle accidents accounted for $67.8 \%$ of all road accidents. However, in Madagascar Rakotoarivony, A.E., et al. [14] reported that motorcycle accidents had a lower incidence than car accidents with the former accounting for $29.3 \%$ while the later accounted for $63.8 \%$ respectively.

The development of the market for two-wheeled motorized vehicles, the possibility of driving them without a license, non-compliance with the highway code, obsolescence and the lack of road infrastructure could explain this high frequency of motorcycle road accidents.

In this study, people of all age groups were affected by maxillofacial injury with no significant difference between cases and controls. The 16 - 30 age group was the most affected with an average age of 28 (for cases) and 29.3 (for controls group) respectively. This group consists of young people who are more likely to move in the course of their daily activities. Chichom-Mefire, et al. [15] in a Cameroonian study reported that the majority of their patients $(57.6 \%)$ were aged 21 - 40 years. Ogini, et al. [9] in Nigeria and Ramli, R., et al. [16] in Malaysia reported an average age of 25.8 and 30.6 years. There is agreement in the literature that men are more affected with motorcycle road accidents [9] [11] [12] [16]. In this study a male predominance was also noted in both groups $(\mathrm{p}=0.001)$. This probably relates to the fact that men use the most motorcycles especially in certain activities such as taxis-motorcycles. Men also participate more often in economic activities, trying to take care of the family. Although no socio-professional layer was spared by road accident, students and pupils were the most affected in both groups $(\mathrm{p}=0.02)$. The predominance of pupils and students could be related to their mobility, in particular their frequent movement during peak hours, the proximity of schools to highways, and non-respect of the highway code. Yusuf, et al. [17] in Nigeria found 17.9\% of students were victims of motorcycle roads accidents. In this study $54.15 \%$ of the patients did not wear a helmet at the time of the accident. This result could be explained by two major factors: patients were passengers and did not wear a helmet and wearing a helmet is considered a heavy weight and creates a feeling of heat, suffocation and leads to limited movement of the head and neck.

The rate of helmet use varies from one country to another. In Iran, it increased from $8.6 \%$ to $75 \%$ (1999-2007) [3]. In Karachi, the rate of wearing a helmet was 56\% [18], Ghana 46\% [2], Indonesia 89\% [4], Brazil 76.3\% [19], and Nigeria $21.5 \%$ [9]. This disparity could be due to cultural behaviors and compulsory helmet wearing in these countries.

This study found that there was a direct relationship between helmet use and 
the occurrence of death $(\mathrm{p}=0.015$, Odds ratio $=4.3)$. This result corroborates the study by Maliska, M.C.S., et al. [19] they reported that helmeted riders have $70 \%$ reduction in injury severity and $40 \%$ reduction in mortality compared to riders without helmets during collisions. In this series we found that motorcycle drivers accounted for 59.02\% of the victims. Ogini, et al. [9] and Yusuf, et al. [17] published similar results. They found $62.7 \%$ and $50.7 \%$ of all victims were motorcycle drivers. This high frequency among drivers could stem from over-speeding, lack of knowledge and non-compliance with the traffic and highway rules, poor condition of motorcycles and poor road infrastructure. In this study, there was no correlation between gear type and FISS $(\mathrm{p}=0.130)$. The score 0 - 3 was the most frequent $(\mathrm{n}=237$ cases) for both groups (motorcycle and car). In Nigeria, Ogini, et al. [9] found that the facial injury severity scale (FISS) ranged from $1-10$ and that the score $0-3$ accounted for $62.4 \%$. Aladelusi A, et al. [20] reported the average FISS of motorcycle and auto road accident as 4 and 9 respectively.

In this study, there was no direct relation between death and the type of device causing the trauma $(p=0.882)$. Failure to include registered body deposition cases in the emergency room may explain this result. In Australia, for example, motorcycle fatality and serious injury rates per kilometers travelled are 29 and 37 times higher than for other vehicle types.

This study showed that when one is a victim of a motorcycle road accident, he or she is more likely to suffer a fracture of the face compared to a victim of an automobile road accident $(\mathrm{p}=0.01)$. This could be explained by the failure of riders to use helmets and the lack of external protection for victims of motorcycle road accident. This result is different from that of Nóbrega, L.M., et al. [13]. They report the prevalence of facial trauma was lower among motorcycle accident victims than in motor vehicle accidents $(\mathrm{p}=0.001)$. Victims of motorcycle accident were more likely to suffer a mandibular fracture compared to victims car accidents $(\mathrm{p}=0.029$, Odds ratio $=1.63)$.

Since the mandible is the bumper of the lower floor of the face with multiple lines of weakness that makes it vulnerable to fractures, low rates of helmet use and the lack of external protection of motorcycle victims can explain these results. Batista, A.M., et al. [21] reported motorcycle accidents were found to be the main risk factor for mandibular fractures $(\mathrm{PR}=1.576, \mathrm{CI}=1.402-1.772)$. In our study there was a correlation between the occurrence of a midface fracture and type of gear $(p=0.029$, Odds ratio $=1.68)$. This result would be related to low rate of helmet use and the lack of external protection of motorcycle victims. Batista, A.M., et al. [21] found motorcycle road accident as the principal risk factor for maxillary fractures $(\mathrm{OR}=11.032, \mathrm{CI}=5.294-22.989)$. There was no difference between head trauma and type of device which caused the trauma ( $p$ $=0.487)$, it is the same for the Glasgow score $(\mathrm{p}=0.709)$. This result is related to the fact that the face and the skull are two anatomically close areas and direct antero-posterior shocks on the face will have repercussions on the skull and/or its contents. Brain injuries have been described as the most common associated 
concomitant body injury with facial fractures [22]. A highly variable incidence of head injuries associated with facial trauma has been reported in various studies [23]. Sounouvou, et al. [24], Martin, et al. [25] reported head injury rates in patients with a maxillofacial injury of $62 \%$ and $79.4 \%$ respectively. In Iran, Zandi, M., et al. [23] performed a logistic regression analysis demonstrating motorcycle accidents and car accidents were the strongest predictors of head injuries. In Brazil, Cavalcanti, A.L., et al. [26] noted a significant association between motorcycle accidents and the occurrence of head injuries $(\mathrm{p}<0.001, \mathrm{PR}=$ $0.310 .95 \% \mathrm{CI}=0.156-0.616)$. In this series, the difference was not significant between the occurrence of maxillofacial injuries and gear type $(\mathrm{p}=0.221)$. It was significant when it involved lesions of the lower and upper limbs $(\mathrm{p}=0.035)$. These areas represent areas of relatively exposed motorcyclists, and are subject to direct or indirect shocks. In contrary to a car crash, the riders often absorb all kinetic and compressive energy resulting from a motorcycle crash [27]. Cavalcanti, A.L., et al. [26] also found a significant association between motorcycle accidents and lower limb injuries $(\mathrm{p}<0.05, \mathrm{PR}=1.765,95 \% \mathrm{CI}=1.029-3.029)$. However, no link was noted between motorcycle accidents and upper limb injuries $(\mathrm{p}>0.05)$.

In this study we noted that there was a significant difference between the duration of follow-up of patients and the type of gear. This difference is due to that patients who suffered traumas by motorcycle were more exposed to facial fractures and needed a longer follow-up.

In our series, dental sequelae were most common with a significant difference between cases and controls $(\mathrm{p}<0.05)$. This could be explained by low helmet use and the role of the maxillae and teeth as a parachoc of the face. Jayasundera, K.S., et al. [28] believe that maxillofacial trauma can cause emotional shock because it leads to permanent scarring, facial asymmetry, and functional problems of chewing and vision. Rajay, A., et al. [29] in 2012 in India reported that the most common complications were infection and occlusal disharmony after surgery.

There are some limitations in this study. First, the study covered a limited number of topics and was conducted over a limited period of time (six (06) months), so it may not be sufficient enough to capture all the parameters that could vary significantly in other studies with larger samples and longer periods of study.

\section{Conclusions}

Maxillofacial trauma due to motorcycle road accident is becoming more common in Guinea, affecting mainly the young adult male. The death rate in relation to these road accidents is high. In this study, there was a statistically significant relationship between helmet use and death.

Mandatory use of a helmet for all drivers and passengers, as well as increased attention and preventive actions, would reduce the mortality and morbidity related to motorcycle road accidents. 


\section{Conflicts of Interest}

The authors declare no conflicts of interest regarding the publication of this paper.

\section{References}

[1] Raux, M. and Bertolus, C. (2012) Traumatismes de la face: Traumatologie vitale. Urgence, Paris, 1-11.

[2] Akaateba, M.A., Yakubu, I., Afiik, B. and Akanbang, A. (2015) Correlates and Barriers Associated with Motorcycle Helmet Use in Wa, Ghana. Traffic Injury Prevention, 16, 809-817. https://doi.org/10.1080/15389588.2015.1024833

[3] Day, L., Lenné, M.G., Symmons, M., Hillard, P., Newstead, S., Allen, T., et al. (2013) Population Based Case-Control Study of Serious Non-Fatal Motorcycle Crashes. BMC Public Health, 13, 72-77. https://doi.org/10.1186/1471-2458-13-72

[4] Faryabi, J., Rajabi, M. and Alirezaee, S.S. (2014) Evaluation of the Use and Reasons for Not Wearing a Helmet by Motorcyclists Admitted to the Emergency Ward of Shahid Bahonar Hospital in Kerman. Archives of Trauma Research, 3, 19122-19127. https://doi.org/10.5812/atr.19122

[5] Li, Y., Qiu, J., Liu, G.D., Zhou, J.H., Zhang, L., Wang, Z., et al. (2008) Motorcycle Accidents in China. Chinese Journal of Traumatology, 11, 243-246. https://doi.org/10.1016/S1008-1275(08)60050-4

[6] Oliveira, A.L., Petroianu, A., Gonçalves, D.M.V., Pereira, G. and Alberti, L.R. (2015) Characteristics of Motorcyclists Involved in Accidents between Motorcycles and Automobiles. Revista da Associação Médica Brasileira, 61, 61-64. https://doi.org/10.1590/1806-9282.61.01.061

[7] Diallo O.R., Souare, I.S., Bah, A.T. and Camara, A.D. (2010) Les urgences traumatiques maxillo-faciales au CHU de Conakry: Aspects épidémiologique, clinique et thérapeutique. Revue du Collège d'Odonto-Stomatologie Africain et de Chirurgie Maxillo-Faciale, 1, 44-48.

[8] Kevan, G.N., Alfredo, L.N., Bruno, D., et al. (2014) Injuries and Absenteeism among Motorcycle Taxi Drivers Who Are Victims of Traffic Accidents. Journal of Forensic and Legal Medicine, 26, 15-18. https://doi.org/10.1016/j.jflm.2014.03.008

[9] Oginni, F.O., Ajike, S.O., Obuekwe, O.N., et al. (2009) A Prospective Multicenter Study of Injury Profile, Severity and Risk Factors in 221 Motorcycle-Injured Nigerian Maxillofacial Patients. Traffic Injury Prevention, 10, 70-75. https://doi.org/10.1080/15389580802496968

[10] Giraud, O., Soultrait, F., Goasguen, O., et al. (2008) Traumatismes cranio-faciaux. Encycl. méd. Chir stomatologie, 22-068-A 10, 13.

[11] Ashu, M.A., Azodo, C.C., Ebot, E.B., et al. (2014) Dentofacial Injuries in Commercial Motorcycle Accidents in Cameroon: Pattern and Cost Implication of Care. African Health Sciences, 14, 77-82. https://doi.org/10.4314/ahs.v14i1.12

[12] Bagheri, S.C., Dierks, E.J., Kademani, D., et al. (2006) Application of a Facial Injury Severity Scale in Craniomaxillofacial Trauma. Journal of Oral and Maxillofacial Surgery, 64, 408-414. https://doi.org/10.1016/j.joms.2005.11.013

[13] Nóbrega, L.M., Cavalcante, M.S.G., Lima, M.S.M., et al. (2014) Prevalence of Facial Trauma and Associated Factors in Victims of Road Traffic Accidents. American Journal of Emergency Medicine, 32, 1382-1386.

https://doi.org/10.1016/j.ajem.2014.08.054 
[14] Rakotoarivony, A.E., Rakotoarison, R.A., Rakotoarimanana, F.V., et al. (2014) Epidémiologie des traumatismes dento-maxillo-faciaux au CENHOSOA Antananarivo. Médecine Buccale Chirurgie Buccale, 20, 221-226. https://doi.org/10.1051/mbcb/2014026

[15] Chichom-Mefire, A., Atashili, J., Tsiagadigui, J.G., et al. (2015) A Prospective Pilot Cohort Analysis of Crash Characteristics and Pattern of Injuries in Riders and Pillion Passengers Involved in Motorcycle Crashes in an Urban Area in Cameroon: Lessons for Prevention. BMC Public Health, 15, 915-923.

https://doi.org/10.1186/s12889-015-2290-4

[16] Ramli, R., Rahman, R.A., Rahman, N.A., et al. (2008) Pattern of Maxillofacial Linjuries in Motorcyclists in Malaysia. Journal of Craniofacial Surgery, 19, 316. https://doi.org/10.1097/SCS.0b013e318163f94d

[17] Yusuf, A.S., Odebode, T.O., Salaudeen, A.G., et al. (2013) Socio-Demographic Profiles and Outcome of Motorcycle Related Head Injury in a Nigerian Tertiary Health Institution. Sahel Medical Journal, 16, 116-120. https://doi.org/10.4103/1118-8561.121921

[18] Khan, I., Khan, A., Aziz, F., Islam, M. and Shafqat, S. (2008) Factors Associated with Helmet Use among Motorcycle Users in Karachi, Pakistan. Academic Emergency Medicine, 15, 384-387. https://doi.org/10.1111/j.1553-2712.2008.00049.x

[19] Maliska, M.C.S., Borba, M., Asprino, L., et al. (2012) Helmet and Maxillofacial Trauma: A 10-Year Retrospective Study. Brazilian Journal of Oral Sciences, 11, 125-129.

[20] Aladelusi, A., Akinmoladun, I.V., Olusanya, O.O., et al. (2014) Evaluation of Pedestrian Road Traffic Maxillofacial Injuries in a Nigerian Tertiary Hospital. African Journal of Medicine and Medical Sciences, 43, 353-359.

[21] Batista, A.M., Ferreira, F.O., Marques, L.S., et al. (2012) Risk Factors Associated with Facial Fractures. Brazilian Oral Research, 26, 119-125. https://doi.org/10.1590/S1806-83242012000200006

[22] Ogundipe, O.K., Afolabi, A.O. and Adebayo, O. (2012) Maxillofacial Fractures in Owo, South Western Nigeria. A 4 Year Retrospective Review of Pattern and Treatment Outcome. Dentistry, 2, 132.

[23] Zandi, M. and Seyed Hoseini, S.R. (2013) The Relationship between Head Injury and Facial Trauma: A Case-Control Study. Oral and Maxillofacial Surgery, 17, 201-207. https://doi.org/10.1007/s10006-012-0368-Z

[24] Sounouvou, I., Zoumenou, E., Alamou, S., et al. (2014) Eye Traumas in the Emergency Department of University Hospital of Cotonou. Ramur, 2, 23-26.

[25] Martin, R.C., Spain, D.A. and Richardson, J.D. (2002) Do Facial Fractures Protect the Brain or Are They a Marker for Severe Head Injury? The American Surgeon, 68, 477-481.

[26] Cavalcanti, A.L., Olinda, R.A., Padilha, W.N., et al. (2017) Motorcycle-Related Cranio-Maxillofacial Injuries among Brazilian Children and Adolescents. Biomedical and Pharmacology Journal, 10, 1603-1609. https://doi.org/10.13005/bpj/1271

[27] Janmohammadi, N., Pourhossein, M. and Hashemi, S.R. (2009) Pattern of Motorcyclist's Mortality in Mazandran Province, Northern Iran. Iranian Red Crescent Medical Journal, 11, 81-84.

[28] Jayasundera, K.S. and Navaratne, G. (2016) A Study on the Pattern of Maxillofacial Trauma Due to Motorcycle Accidents and the Influence of Helmets. Sri Lanka Dental Journal, 46, 96-101.

[29] Rajay, A.D., Kamath, B.D.S., Shiva Bharani, K.S.N., et al. (2012) Maxillofacial 
Trauma in Central Karnataka, India: An Outcome of 95 Cases in a Regional Trauma Care Centre. Craniomaxillofacial Trauma \& Reconstruction, 5, 197-204.

https://doi.org/10.1055/s-0032-1322536 